\title{
The Role of Lumbar Puncture in Management of Idiopathic Intracranial Hypertension (IIH)
}

\author{
KHALED I. ABD EL-AZIZ, M.D.* and AYMAN M. EL-DEMRDASH, M.D.** \\ The Departments of Neurosurgery* and Anesthesiology**, Aswan University Hospital, Aswan, Egypt
}

\begin{abstract}
Background: Idiopathic Intracranial Hypertension (IIH) is characterized by clinical manifestations of elevated intracranial pressure, normal CSF content, and by neuroimaging studies revealed normal brain with normal or small sized ventricle.
\end{abstract}

Aim of Work: The purpose of this study is to assess clinical, ophthalmological and neuroimaging studies of IIH and the role of lumbar puncture in treatment of IIH.

Patients and Methods: This is a prospective study of forty-patients were included in the study. All patients underwent clinical, ophthalmological, imaging, laboratory investigation and CSF manometry evaluations. All patients take chance for Lumbar Puncture (LP). Analysis of data was conducted and evaluation of outcome was assessed.

Results: Lumbar Puncture (LP) either once or multiple sessions used for treating intractable headaches and visual impairment associated with IIH with success rate of $90 \%$.

Conclusion: Lumbar puncture is considered a high successful treatment option for IIH.

Key Words: Idiopathic intracranial hypertension - Papilledema - Headache-Opening pressure lumbar puncture.

\section{Introduction}

IDIOPATHIC Intracranial Hypertension (IIH) is a disorder associated with manifestations of Increased Intracranial Pressure (ICP) and not included with infection, intracranial space-occupying lesion, hydrocephalic changes, cerebrovascular abnormalities, or alteration of conscious level [1]

IIH was termed pseudo tumor cerebri and benign intracranial hypertension, but with the advanced of neuroimaging and the greater understanding of its associated loss of vision, those terms not

Correspondence to: Dr. Khaled I. Abd El-Aziz, E-Mail: khaledis2020@yahoo.com used. IIH is defined by the revised Modified Dandy Criteria, which include:

- Manifestations of increased ICP.

- No signs except an abducent nerve palsy.

- Normal neuroimaging that does not identify the aetiology for elevated ICP.

- Cerebrospinal Fluid (CSF) opening pressure at least $25 \mathrm{cmH}_{2} \mathrm{O}$ with normal CSF content [1].

The most common manifestations of IIH are headache, transient visual obscurations, and tinnitus [2], also patients may complain of blurred vision, double vision due to abducent nerve palsies, or retrobulbar pain. Papilledema may be rang from mild blurring of the disc margins up to gross disc swelling with hemorrhages and exudates, which considered a diagnostic finding of IIH. The disc edema is generally bilateral, but it can be asymmetrically. Untreated papilledema can lead to optic atrophy and visual loss in up to one third of patients $[3,4]$.

The pathogenesis of IIH is not known. But by different mechanisms it may be analyzed as, increased in the cerebral blood volume, increased CSF secretion and brain edema $[\mathbf{5 , 6}]$.

Elevated venous pressure may lead to increase CSF absorption resistance, subsequently increasing cerebrospinal pressure [7].

The pathophysiological mechanism of IIH is may be due to (1) a decreased rate of CSF absorption, (2) an increased rate of CSF formation, (3) an increase in interstitial fluid volume simulating brain edema, and (4) a sustained increase in intracranial venous pressure $[8]$

Various conditions such as menstrual irregularities, pregnancy, oral contraceptives, endocrine 
disturbances, corticosteroid therapy and its withdrawal, nitrofurantoin, nalidixic acid, and tetracycline therapy, anemia, hyper and hypovitaminosis A, spinal cord tumors, and Guillain-Barre syndrome have been described as associated with IIH [9] .

Another mechanisms may contribute to acute IIH manifestation, sinus thrombosis lead to disturbance of cerebral venous outflow and traumatic depressed fracture on superior sagittal sinus (especially posterior third or confluence of sinuses) which may lead to the clinical syndrome of IIH [10!

Also, hormones may play a role in the etiology of IIH since IIH particularly affects obese women

Lumbar Puncture (LP) is a minimally invasive procedure performed for both diagnostic and therapeutic evaluation [12]

LP is widely considered a safe procedure, but it is not a risk-free. The most reported complication of LP is post-LP headache which may occur in $25 \%$ of patients [13].

\section{Patients and Methods}

This is a prospective study carried out between May 2014 and November 2017, included forty adult patients were diagnosed with idiopathic intracranial hypertension based on clinical (full neurological and ophthalmological evaluation including visual acuity, fundus examination and perimetry) and imaging (neuroimaging studies include MRI brain and MRV) data and all patients prior to lumbar puncture asked for prothrombin time, concentration and partial thromboplastin time to roll out coagulation impairment. All patients were evaluated and treated at the Department of Neurosurgery, Aswan University Hospital. All patients received Lumbar Puncture (LP) as an initial treatment. Among the population studied, 36 patients $(90 \%)$ responded to LP (single or multiple series) showing recovery of symptoms and resolution of papilledema, whereas 4 patients $(10 \%)$ failed to respond to LP and required lumboperitoneal shunt placement. Lumbar Puncture (LP) is a minimally invasive procedure performed for both diagnostic and therapeutic evaluation. The lumbar puncture used therapeutically in temporarily relieving symptoms and signs of raised ICP. Ideally, the patient should be placed in the lateral recumbent position which will allow for opening pressure measurements. Although the lumbar puncture may be performed at the bedside or in an outpatient clinic, it is often necessary to perform it under local anesthesia using $20 \mathrm{G}$ needle that was inserted under complete aseptic precautions in L4-5 vertebral space.

Patients' evaluation: All patients completely evaluated clinically, that included neurological, and ophthalmological examinations. Analysis of manifestations of increased intracranial pressure for all patients through the same questionnaire for headache, vomiting, visual impairment, and pulsatile tinnitus were recorded. Ophthalmic examination included visual acuity testing using Snellen chart, fundus examination, and visual field testing using Goldmann perimetry. Presenting clinical manifestations were recorded.

Magnetic Resonance Imaging (MRI) brain was done to all patients. Lumbar puncture was done and manometry was recorded, and CSF sample for physical and chemical analysis was done. The opening CSF pressure was measured with the patient in the lateral decubitus position. We classified CSF pressure into 4 groups: Mild (20--<30 $\mathrm{CmH}_{2} \mathrm{O}$ ), moderate $\left(30-<40 \mathrm{CmH}_{2} \mathrm{O}\right)$, severe (40$\left.<50 \mathrm{CmH}_{2} \mathrm{O}\right)$, and fulminant $\left(\geq 50 \mathrm{CmH}_{2} \mathrm{O}\right)$. Serial opening CSF pressures were recorded and response to LP was classified into regressive, intermittent, stationary, and progressive.

Surgical intervention: For surgical treatment of IIH included patients with severe visual loss at initial presentation or persistent visual deficit who failed despite repeated lumbar CSF drainage. Four patients were failed for repeated lumbar puncture and undergone thecoperitoneal shunt was applied as a one piece model.

Follow-up: Clinical follow-up was assisted at 1,3 , and 6 month intervals. Asking for persisting headache after treatment was done for all patients. Fundus examination was evaluated for resolution of papilledema, and visual field was monitored for resolution of visual field defects.

\section{Results}

The study group included 40 cases $(100 \%)$ females. The age range was $20-38$ years (mean age, 28.5 years). Fundus examination revealed bilateral papilledema in $40(100 \%)$ patients with different degrees of papilledema. Visual field $a b-$ normalities included enlarged blind spot in $4(10 \%)$ patients, unilateral scotoma in $4(10 \%)$ patients, bilateral scotoma in 28 (70\%) patients, and peripheral field constriction in $4(10 \%)$ patients. Convergent squint was present in $4(10 \%)$ patients who had unilateral abducent nerve palsy. 
Diagnostic data: On non-contrast MRIs, ventricular size was within normal limits in $20(50 \%)$ patients. The ventricles were slit like in $20(50 \%)$ patients. The sella was normal among $15(37.5 \%)$ patients, whereas $25(62.5 \%)$ patients had an empty sella. Among all patients, the opening CSF pressure (OP) for the first lumbar puncture was moderate (OP between 30 to $40 \mathrm{CmH}_{2} \mathrm{O}$ ) in $36(90 \%)$ patients, severe (OP between 40 to $50 \mathrm{CmH}_{2} \mathrm{O}$ ) in $3(10 \%)$ patients, and fulminant in 1 case (OP more than $50 \mathrm{CmH}_{2} \mathrm{O}$ ). Response to first time of lumbar puncture was $10(25 \%)$ patients, repeated times of lumbar puncture (more than once LP) was $26(65 \%)$ patients, and failure to response (more than 3 times) in $4(10 \%)$ patients. The amount of CSF sample obtained was 20 to $30 \mathrm{CC}$ (cubic $\mathrm{cm}$.).

Among this group, 36 (90\%) patients were free of headache and follow-up fundus examination revealed resolution of papilledema. Significant predictors for surgical treatment included severe CSF opening pressures, presence of slit ventricles on imaging studies, and poor response to repeated lumbar puncture as four patients who underwent surgery.
Table (1): Summary of clinical, ophthalmological, neuroimaging and results of forty patients with $\mathrm{IIH}$.

\begin{tabular}{|c|c|}
\hline Number of patients & Forty patients \\
\hline Age: & 20-38 years \\
\hline Obesity: & All cases \\
\hline Degree of papillodema: & $\begin{array}{l}\text { ( } 1 \text { st degree to } 4 \text { th degree) } \\
15 \text { cases } 1 \text { st to } 2 \text { nd degree } \\
20 \text { cases } 2 \text { nd to degree } \\
5 \text { cases } 3 \text { to } 4 \text { th degree }\end{array}$ \\
\hline Visual field: & $\begin{array}{l}4 \text { cases enlarged blind spot } \\
4 \text { cases unilateral scotoma } \\
28 \text { cases bilateral scotoma } \\
4 \text { cases peripheral field constriction }\end{array}$ \\
\hline Neurological disorder: & 4 cases 6 th nerve palsy \\
\hline Lumbar puncture response: & $\begin{array}{l}\text { 1st time LP--- } 10 \text { cases } \\
\text { Repeated-- LP } 26 \text { cases } \\
\text { Failure } 4 \text { cases }\end{array}$ \\
\hline Thecoperitoneal shunt: & 4 cases \\
\hline MRI finding: & $\begin{array}{l}20 \text { cases---normal ventricular size } \\
20 \text { cases slit ventricle } \\
15 \text { cases---normal sella turcica } \\
25 \text { cases---empty sella turcica }\end{array}$ \\
\hline Opening pressure: & $\begin{array}{l}\text { Moderate-- } 36 \text { cases } \\
\text { Severe-- } 3 \text { cases } \\
\text { Fulminant-- } 1 \text { case }\end{array}$ \\
\hline
\end{tabular}

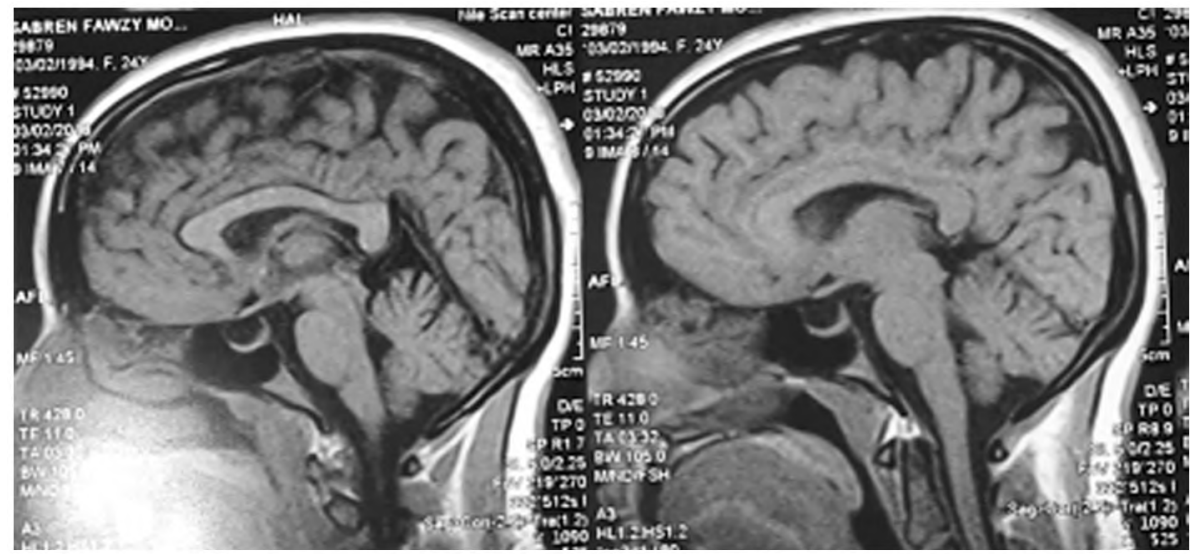

Fig. (1): MRI brain sagittal view revealed empty sella syndrome.

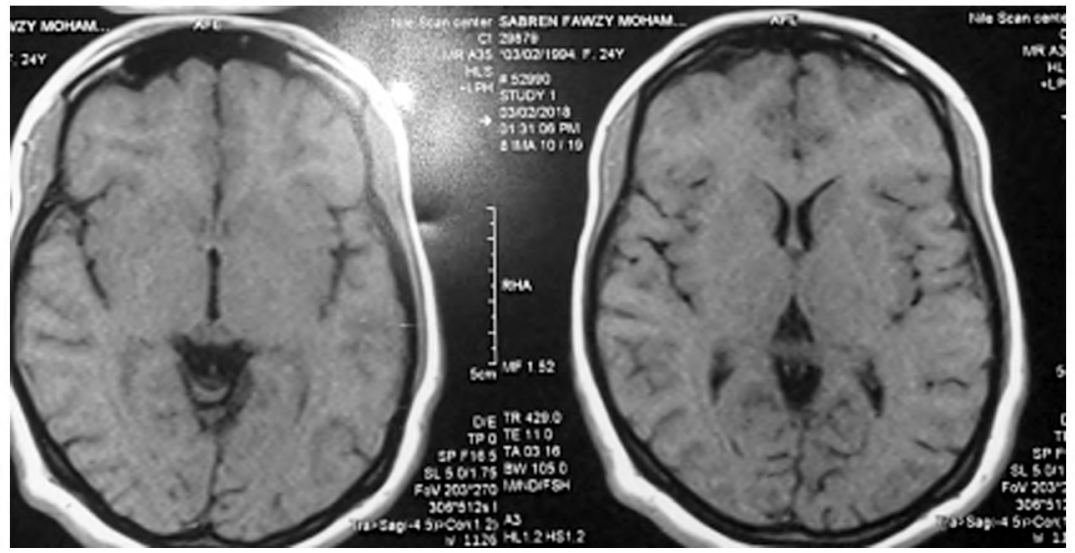

Fig. (2): MRI brain axial viiew revealed slit ventricle. 

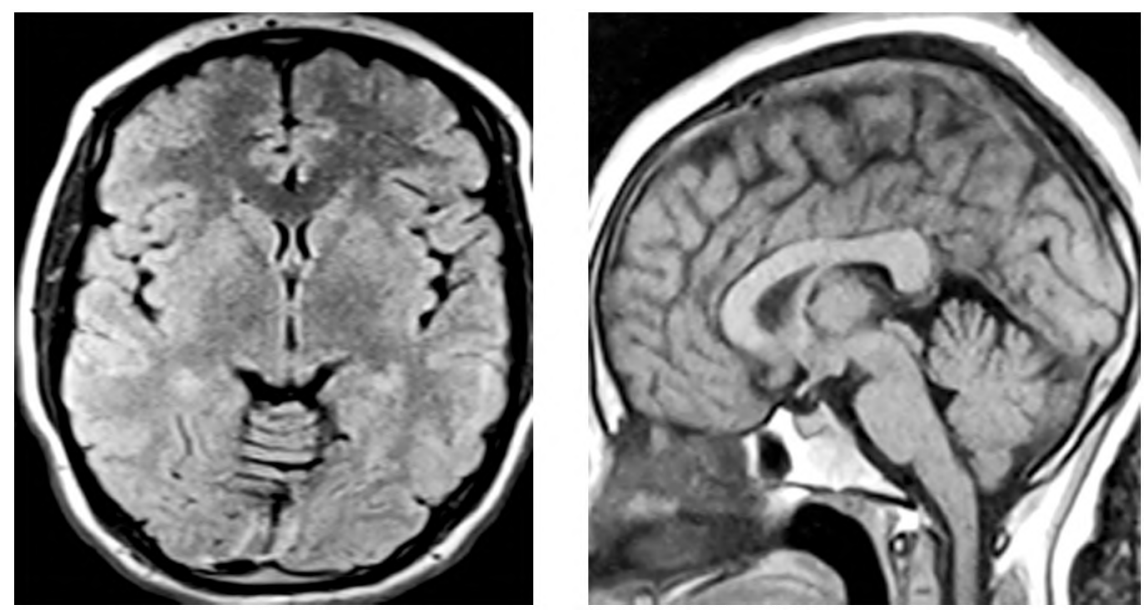

Fig. (3): MRI of a case of advanced papillodema and $6^{\text {th }}$ nerve palsy.

\section{Discussion}

Idiopathic Intracranial Hypertension (IIH) is not a single disease but it has a complex syndrome in its presentation [1]

The pathophysiology of IIH related to CSF hydrodynamic and neuroimaging studies [15].

Treatment of IIH includes different modalities which include medical treatment, lumbar puncture, and surgery [14]

Recovery is often observed as regression of papilledema which is thought to be return of CSF pressure to its normal value, yet CSF pressure may be persistently elevated after the initial occurrence of IIH.

In this study we found that all patients were females and were overweight which accept that obesity could contribute to the pathogenesis of IIH.

The mechanism of obesity in IIH, it increases the intra-abdominal pressure, which increase pleural pressure and cardiac filling pressures, that reduces venous return from the brain and leads to elevated intracranial pressure [15]

Bagga et al., (2005) investigated three pregnant cases with IIH and all cases were obese and all symptoms were resolved postpartum [16].

Aggressive weight reduction is necessary in obese patients as weight loss are considered effective role of IIH treatment [17].

All patients diagnosed with IIH need LP after neuroimaging tools done to exclude any intracranial space occupying lesions. Lumbar puncture is the effective technique for treatment of IIH because it directly reduces intracranial pressure immediately [18] .

Surgical management for treating patients with persistent IIH manifestations after failure of repeated Lumbar Puncture (LP) using CSF diversion techniques which are the most commonly used, its properties are minimal invasiveness, and tolerable and easily managed morbidities. They include thecoperitoneal shunt or ventriculoperitoneal shunt with stereotactic guidance or free handing [19].

We found LP to be effective in lowering of intracranial pressure in patients with IIH. Headache and papilledema resolved completely in $90 \%$ of patients after LP.

In this study, all patients underwent LP as a single or multiple modality effective to relieve CSF pressure.

Badve et al., (2011) reported that repeated LP and spinal taping can help improving symptoms of IIH and preventing permanent vision loss with good results as in our study [17]

\section{Conclusion:}

IIH is uncommon disease characterized by manifestations of increased intracranial pressure without neuroimaging or laboratory abnormalities of the brain, which affects mostly young and middle aged overweight females.

Lumbar puncture either single or multiple sessions can control IIH safely with success rate $90 \%$, with special care to those cases with progressive deterioration of vision despite of repeated lumbar puncture in which CSF diversion shunt may be needed. 


\section{References}

1- FRIEDMAN D.I. and JACOBSON D.M.: Diagnostic criteria for idiopathic intracranial hypertension. Neurology, 59: 1492-5, 2002

2- GIUSEFFI V., WALL M., SIEGEL P.Z. and ROJAS P.B.: Symptoms and disease associations in idiopathic intracranial hypertension (pseudotumor cerebri): A case-control study. Neurology, 41: 239-44, 1991.

3- CORBETT J.J., SAVINO P.J. and THOMPSON H.S. Visual loss in pseudotumor cerebri: Follow-up of 57 patients from five to 41 years and a profile of 14 patients with permanent severe visual loss. Arch. Neurol., 39: 461-74, 1982.

4- WALL M. and GEORGE D.: Idiopathic intracranial hypertension. A prospective study of 50 patients. Brain, 114 (Pt IA): 155-80, 1991.

5- IRELAND B., CORBETT J.J. and WALLACE R.B.: The search for causes of idiopathic intracranial hypertension. A preliminary case-control study. Arch. Neurol., 47: 31520,1990

6- WALL M.: Idiopathic intracranial hypertension. Neural. Clin., 28: 593-617, 2010.

7- BARYSHNIK D.B. and FARB R.I.: Changes in the appearance of venous sinuses after treatment of disordered intracranial pressure. Neurology, 62: 1445-6, 2004.

8- DONALDSON J.O.: Pathogenesis of pseudotumor cerebri syndromes. Neurology, 31: 877-80, 1981.

9- FISHMAN R.A.: The pathophysiology of pseudotumor cerebri. Arch. Neurol., 41: 257-8, 1984.

10- D'AVELLA D., GREENBERG R.P., MINGRINO S. SCANARINI M. and PAR-DATSCHER K.: Alterations in ventricular size and intra-cranial pressure caused by sagittal sinus pathology in man. J. Neurosurg., 53: 656$61,1980$.
11- KESLER A. and KUPFERMINC M.: Idiopathic intracranial hypertension and pregnancy. Clinical Obstetrics and Gynecology, 56 (2): 389-96, 2013.

12- JOHNSON K.S. and SEXTON D.J.: Lumbar puncture: Technique, indications, contraindications and complications in adults. In: Post T.W., editor. Up To Date. Waltham, MA: UpToDate; 2015.

13- BASURTO O.X., MARTINEZ G.L. and BONFI LL C.X. Drug therapy for treating post-dural puncture headache. Cochrane Database Syst. Rev., 8: CD007887, 2011.

14- BOUSSER M.G.: Cerebral venous thrombosis, diagnosis and management. J. Neurol., 247: 252-8, 2000.

15- KARAHALIOS D.G., REKATE H.L., KHAYATA M.H. and APOSTOLIDES P.J.: Elevated intracranial venous pressure as a universal mechanism in pseudotumor cerebri of varying etiologies. Neurology, 46: 198-202, 1996.

16-BAGGA R., JAIN V., DAS C.P., GUPTA K.R., GOPALAN S. and MALHOTRA S.: Choice of therapy and mode of delivery in idiopathic intracranial hypertension during pregnancy. Medscape General Medicine, 7 (4): 42-6, 2005 .

17- BADVE M., McCONNELL M., SHAH T., ONDECKOLIGDA K., POUTOUS G. and VALLEJO M.: Idiopathic intracranial hypertension in pregnancy treated with serial lumbar punctures. International Journal of Clinical Medicine, 2 (1): 9-12, 2011.

18- ABOULEIS H.E., ALI V. and TANG R.A.: Benign intracranial hypertension and anesthesia for cesarean section. Anesthesiology, 63 (6): 9705-7, 1985.

19- ABU-SERIEH B., GHASSEMPOUR K., DUPREZ T. and RAFTOPOULOS C.: Stereotactic ventriculoperitoneal shunting for refractory idiopathic intracranial hypertension. Neurosurgery, 60: 1039-44, 2007.

\section{دور البزل القطنى فى علاج إرتفاع ضغط المخ مجهول السبب}

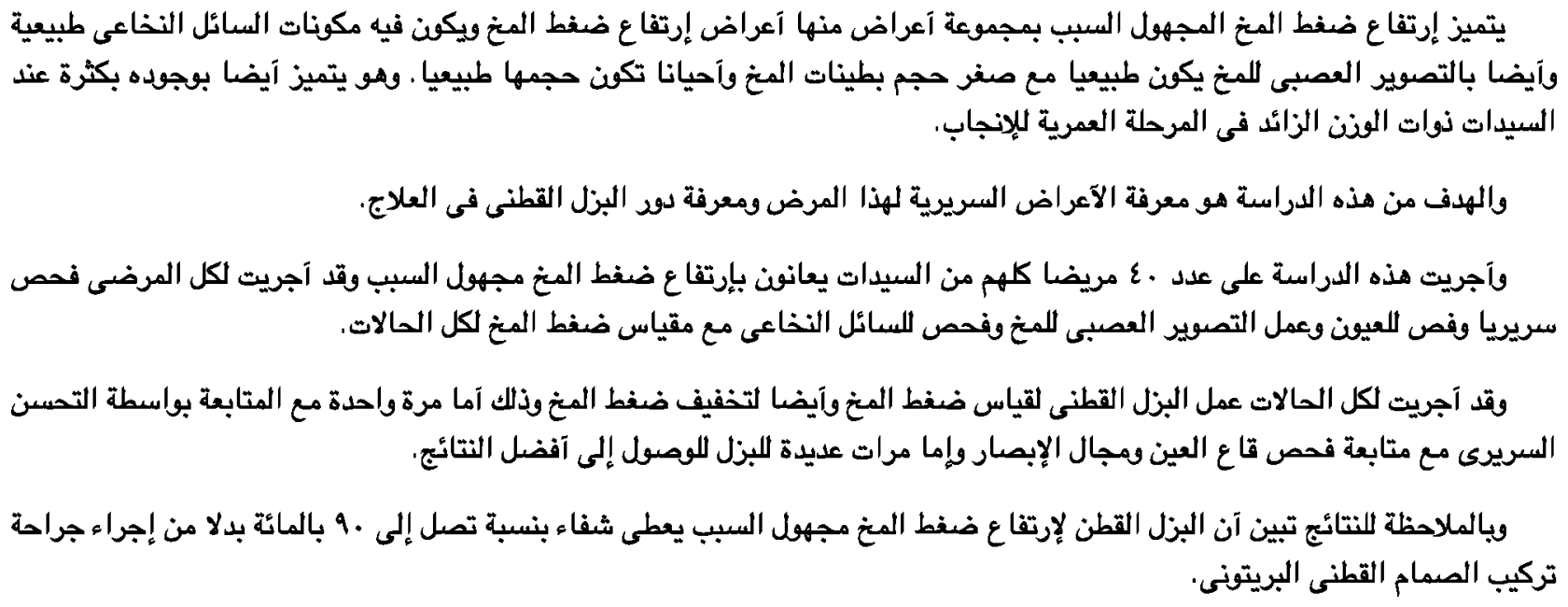

